\title{
Spiritual interventions in Iran: A review article
}

\author{
Nadereh Memaryan ${ }^{1}$, Zeinab Ghaempanah ${ }^{2 *}$ and Ruohollah Seddigh ${ }^{3}$ \\ ${ }^{1}$ School of Behavioral Sciences and Mental Health (Excellence Center of Psychiatry and Clinical Psychology), Iran University of Medical Sciences, \\ Tehran, Iran \\ ${ }^{2}$ The office of Islamic studies in Mental Health, School of behavioral sciences and mental health. Iran University of Medical Science, Tehran, Iran \\ ${ }^{3}$ Mental Health Research Center, Iran University of Medical Sciences, Tehran, Iran
}

\begin{abstract}
Received: 28 December, 2016; Accepted: February 18, 2017; Published: February 25, 2017
*Corresponding author: Zeinab Ghaempanah, The office of Islamic studies in mental health, School of behavioral sciences and mental health, Iran University of Medical Science, Tehran, Iran, Tel: +98 21 66551653, +98 912 3846206. E-mail: zeinab.Ghaempana@gmail.com
\end{abstract}

\begin{abstract}
Objectives: Although many studies have examined the effects of spiritual interventions, ambiguity of the model of them causes bias. This study aimed to achieve a picture of spiritual interventions in Iran as a Shiite Muslim country.

Method: An advanced search was conducted in main Iranian and international databases using both the English and Persian keywords of spiritual intervention, spiritual care, spiritual therapy, spiritual support, and spirituality. Iranian studies that indexed until May 2016 and were related to the effects of spiritual therapies in clinical trials were selected.

Results: Out of the 31selected articles, 17 were in Persianlanguage journals, and 14 were in English-language journals. The interventions that have presented in these articles were classified into three main categories: research-based interventions, mixed interventions and arbitrary interventions.
\end{abstract}

Conclusion: No clear model for spiritual interventions can be extracted from Iranian studies.

Keywords: Clinical Trials: Iran: Spirituality: Spiritual Therapy

What is already known about the topic?

- In recent decades, spiritual care has been added to the collection of patients care

- There is no clear definition of spiritual care and it often overlap with religious concepts

- There is too much diversity in spiritual clinical trial interventions

What this paper adds?

- Even though Iran is among the six countries with the most studies in this area, it appears design of spiritual interventions in Iranian clinical trials are not based on a specific study to find the best spiritual/religious interventions for their study group

\section{Introduction}

Based on Iranian context, spirituality is the sublime aspect of human existence bestowed on all humans in order for them to traverse the path of transcendence that is closeness to God
(Allah). Accordingly, the concepts of spirituality and religion are thus inseparable, although not in the sense that they are one and the same, but in the sense that religion is necessary for spiritual improvement [1].

Spiritual care as patient needs is a dynamic and subjective concept and refers to healing presence, therapeutic use of self, intuitive sense, exploration of the spiritual perspective, patientand meaning-centered interventions, and creation of a spiritual environment [2]. Spiritual care can be integrated into other aspects of care and influence treatment decisions and with facilitation of coping and healing can influence prognosis and quality of life [28]. On the other hand, a wrong approach to spiritual intervention is not only unethical, but it can also increase the burden of disease instead of reducing it $[9,10]$. Among patients, there is also a tendency to incorporate spiritual/religious interventions in normal care services $[11,12]$. Therefore, in recent decades, "spiritual care" has been added to the collection of patients care and has accompanied the development of research in this area $[13,14]$.

However, there is no single definition of spiritual care. Various concepts and definitions have been given, from religious care that refers to performing some religious rituals to secular care that refers to the individual level experience of care $[15,16]$. In addition, these concepts often overlap with each other. Patient definition of spiritual care is also different from the definition of providers of this kind of services [17]. Cultural, social, and religious variables also have an effect on it $[18,19]$. Additionally, it can cause a feeling of helplessness and confusion in this type of service providers, too much diversity in clinical trial interventions, and finally bias in researches [18,20-22]. Even though Iran is among the six countries with the most studies in this area, it appears such conditions do also exist in Iran [23]. Therefore, this study was designed to answer the following question: what are the spiritual interventions that have been designed for Iranian context in clinical trials. The answer to this question can create 
a picture of spiritual interventions in the Iranian society and also help in the design of future studies.

\section{Methods}

This review study was conducted by an advanced search. In order to find articles, a search was done in www.magiran.com and www.sid.ir for articles published in Persian and in PubMed and Scopus for articles published in English. The search in English-language databases was limited to Iran. The search was performed using the keywords spiritual intervention, spiritual care, spiritual therapy, spiritual support, and spirituality. The Persian equivalents of these keywords were searched in Persianlanguage databases.

After the above search, articles were screened for the following criteria in order to determine their inclusion or exclusion from the study: 1) Iranian first author and corresponding author and an affiliation with either an Iranian university or research center, 2) the measured effect of spiritual intervention in a clinical trial, 3) an Iranian study population, and 4) a published and index date prior to May 2016. Exclusion criteria included: 1) the study having been published more than one time (in which case only one of them was studied), 2) a single intervention on different groups or to assess different outcomes (in these cases, due to the number of articles derived from these studies, only one study entered our research), 3) the uncertainty of the treatment protocol used in the study, and 4) lack of access to the English-language abstract of Persian-language articles.

\section{Results}

After two rounds of screening (including a search of title and abstract and then a search of the full text) 31 articles were selected for data entry. Of these, 17 articles in Persian-language journals and 14 articles in English-language journals were published [24-51]. We categorized the Interventions of these articles into three main categories: 1) research-based interventions, 2) mixed interventions and 3) arbitrary interventions. [Table 1] summarizes the results of the study.

\section{Research-based interventions}

This category refers to the interventions which were based on a specific study to find the best spiritual/religious interventions for their study group in Iranian culture. A total of one article was classified into this category [42].

\section{Mixed interventions}

This category refers to interventions that had been designed by: 1) adding some spiritual and religious concepts to a wellknown model of counselling and psychotherapy, and 2) mixing selected concepts of different models. A total of 13 articles were classified under this category $[24,25,28,31,36,37,39,40,44,45,48$ ,49,52].

\section{Arbitrary interventions}

This category refers to implementing some spiritual/ religious designed by researchers without research background or without using an evidence-based model of spiritual/religious intervention. A total of 17 articles were classified under this category $[26,27,29,30,32-35,38,41,43,46,47,50,51,53,54]$.

\section{Discussion}

The results of the present study show the range of spiritual interventions in patients and healthy subjects, which can be an inspiration to researchers in this field. However, due to the diversity of methods in these studies, a single method for spiritual interventions that suits the cultural and religious context of Iran cannot be achieved, and regarding research, a systematic review or meta-analysis cannot be done. In such circumstances in which few therapeutic models exist and it is expected that researchers in this field create standards by developing clearly identified research boundaries, a number of these studies have used the models of spiritual interventions of other cultures and religions, and some of them have even combined various components and have evaluated their effect as a whole; however, an explanation as to how and why the different sectors of interventions were combined was not provided. In fact, we found just 1 article in clinical trial until May 2016 that implemented interventions based on a specific study to develop culturally appropriate interventions. So a local version of spiritual therapy backed by solid research cannot be achieved. The absence of comparison with other methods of treatment (which in our study, only 5 involved these comparisons), lack of a control group in some studies, and no clear boundary between spiritual and religious interventions are also some cases which contribute to the above problem $[24,27,28,32,34,39,40,42]$. Increased research in this area, strengthening the link between health care researchers and scholars of Islam, focused research on previous research studies in order to improve their generalizability, encouraging the publication of study results in English, and carrying out joint research with other Muslim countries are strategies to promote research in this area.

Limitations of our study are the exclusion of studies that did not have English abstracts and not searching for studies that were performed as theses and therefore not published.

\section{Conclusion}

In most Iranian spiritual clinical trials, interventions are not evidence-base. Interventions are either a mixture or arbitrary selection of some spiritual/religious concepts. So, no clear model for spiritual interventions can be extracted from Iranian studies. 
Table 1: Summary of spiritual interventions in clinical trials in Iran

No. $\quad$ Authors, Year of publication (+Ref. No.) Interventions Research-based interventions

\begin{tabular}{|c|c|c|}
\hline 1 & Ebrahimi A, et al. 2013 (42) & $\begin{array}{l}\text { Interventions designed based on Grounded theory in Islamic sources: being in touch } \\
\text { with reality, positive attitude toward the future, searching for positive change in the } \\
\text { past, finding meaning in hardship, meditation, prayer, relationship with others, and } \\
\text { participation in the activities of spiritual joy }\end{array}$ \\
\hline \multicolumn{3}{|r|}{ Mixed interventions } \\
\hline 1 & Ghahari S, et al. 2012 (28) & $\begin{array}{l}\text { Combining Richards \& Bergin spiritual/religious psychotherapy (55) with Tuck (56) } \\
\text { and Lines(57) spiritual studies and some spiritual/religious concepts }\end{array}$ \\
\hline 2 & Reihani T, et al. 2014 (49) & $\begin{array}{c}\text { Combining Richards \& Bergin spiritual/religious psychotherapy (55) with some Islamic } \\
\text { teachings }\end{array}$ \\
\hline 3 & Hosseini MA, et al. 2013 (44) & $\begin{array}{c}\text { Combining Richards and Bergin's spiritual therapy techniques (55) with some Islamic } \\
\text { supplication and the holy Quran verses }\end{array}$ \\
\hline 4 & Mahdavi B, et al. 2015 (40) & $\begin{array}{c}\text { Adding some spiritual/religious concepts to Richards and Bergin's spiritual therapy } \\
\text { techniques (55) }\end{array}$ \\
\hline 5 & Shafiee Z, et al. 2016 (52) & $\begin{array}{c}\text { Mixing American Psychological Association model for spiritual interventions with some } \\
\text { selected concepts from Iranian spiritual/religious studies }\end{array}$ \\
\hline 6 & Ahmadifaraz M, et al. 2015 (24) & $\begin{array}{c}\text { Implementing a variety of Islamic prayers with using Cognitive Behavior Therapy } \\
\text { principles }\end{array}$ \\
\hline 7 & Taghadosi M, et al. 2014 (37) & $\begin{array}{c}\text { Reviewing stages of life based on Erickson's developmental model, in combination with } \\
\text { some spiritual and religious teachings }\end{array}$ \\
\hline 8 & Salajegheh S, et al. 2014 (36) & $\begin{array}{l}\text { Combining the spiritual healing of Hartz(58) with Beck's model of cognitive behavioral } \\
\text { therapy (59) and teaching some spiritual and religious rituals }\end{array}$ \\
\hline 9 & Yaghubi H, et al. 2012 (39) & $\begin{array}{c}\text { Combining Richards \& Bergin spiritual/religious psychotherapy (55) with some Islamic } \\
\text { teachings }\end{array}$ \\
\hline 10 & Hamdieh M, et al. 2008 (31) & $\begin{array}{l}\text { Combining Richards \& Bergin spiritual-religious psychotherapy (55) with Beck } \\
\text { cognitive behavior therapy (59) and adding some Islamic religious rituals }\end{array}$ \\
\hline 11 & Ravaei F, et al. 2013 (48) & $\begin{array}{c}\text { Combination of some spiritual concepts with reading Koran and some cognitive and } \\
\text { behavioral interventions }\end{array}$ \\
\hline 12 & Jafari N, et al. 2013 (45) & $\begin{array}{l}\text { Cole and Pargament's(60) approach combined with some techniques of behavior therapy } \\
\text { (relaxation and meditation) and Gestalt psychology (two chair)(61)and prayer therapy }\end{array}$ \\
\hline 13 & Asadollahi F, et al. 2014 (25) & $\begin{array}{c}\text { Combination of Enright model (62), Adler and Fagley model (63) and 4-axes model of } \\
\text { person's relationship with self, others, nature, and God }\end{array}$ \\
\hline \multicolumn{3}{|r|}{ Arbitrary interventions } \\
\hline 1 & Lotfi Kashani F, et al. 2012 (34) & $\begin{array}{c}\text { Training of } 6 \text { components: self-awareness, benediction, trust in God, patience, praise, } \\
\text { and asking forgiveness from God }\end{array}$ \\
\hline 2 & Bamdad M, et al. 2013 (26) & Active listening with some spiritual-religious interventions to induce hope \\
\hline 3 & Saeedi Taheri Z, et al. M. 2013 (35) & $\begin{array}{l}\text { An Islamic concept (Ghalb-e-Salim) with a focus on achieving a sense of peace and } \\
\text { security, relaxation, hope, love and happiness }\end{array}$ \\
\hline 4 & Fallahi-Khoshknab M. 2007 (27) & A 10-day pilgrimage to the most famous religious city in Iran (Mashhad) \\
\hline 5 & Gholami A, et al. 2012 (30) & Implementing some selected religious rituals \\
\hline 6 & Ghanbari V, et al. 2012 (29) & $\begin{array}{c}\text { Group reading of the Persian translation of the Koran and discussing the meaning of the } \\
\text { verses }\end{array}$ \\
\hline 7 & Kajbaf MB, et al. 2014 (32) & Training and discussing 10 different Islameic believe and ritual \\
\hline 8 & Taghizadeh ME, et al. 2013 (38) & $\begin{array}{c}\text { Training and discussing } 14 \text { different spiritual-religious and non-spiritual-religious } \\
\text { concepts }\end{array}$ \\
\hline 9 & LotfiKashanai F, et al. 2013 (33) & $\begin{array}{l}\text { Training and discussing self-monitoring, connection to endless power, forgiveness, } \\
\text { anger management, and finding meaning in difficult experiences }\end{array}$ \\
\hline 10 & Moeini M, et al. 2012 (46) & $\begin{array}{c}\text { Supportive presence, supporting patients' religious rituals, and allowing family and } \\
\text { clergymen at the patient's bedside }\end{array}$ \\
\hline 11 & Musarezaie A, et al. 2014 (47) & Supportive presence, and supporting patients' religious rituals \\
\hline 12 & Musarezaie A, et al. 2015 (50) & Supportive presence, and supporting patients' religious rituals \\
\hline 13 & Eskandari N, et al. 2012 (43) & $\begin{array}{c}\text { Recitation of verses } 7 \text { to } 23 \text { of Joseph in the Koran for } 20 \text { minutes with headphones in } \\
\text { the morning with a sound of 50-60 decibels }\end{array}$ \\
\hline 14 & Beiranvand S, et al. 2014 (41) & $\begin{array}{l}\text { Twenty minutes of headphone broadcasting of a prayer associated with healing from } \\
\text { God }\end{array}$ \\
\hline 15 & Zamaniyan S, et al. 2016 (51) & $\begin{array}{c}\text { Communication with inner self and God, Altruism, relationships with holy sites, } \\
\text { forgiveness, fear of death and thanksgiving }\end{array}$ \\
\hline 16 & Hedayati E, et al. 2015 (53) & $\begin{array}{l}\text { Caring presence, supporting religious rituals and reading words of religious scholars } \\
\text { and world's scientists about hope, generosity and forgiveness. }\end{array}$ \\
\hline 17 & Hosseini L, et al. 2016 (54) & $\begin{array}{l}\text { Some spiritual/religious concepts training based on some Quran verses and Islamic } \\
\text { supplications }\end{array}$ \\
\hline
\end{tabular}




\section{References}

1. Memaryan N, Rassouli M, Mehrabi M. Spirituality Concept by Health Professionals in Iran: A Qualitative Study. Evidence-Based Complementary and Alternative Medicine. 2016;2016:9. doi: $10.1155 / 2016 / 8913870$

2. Ramezani M, Ahmadi F, Mohammadi E, Kazemnejad A. Spiritual care in nursing: a concept analysis. International nursing review. 2014;61(2):211-219.doi: 10.1111/inr.12099

3. Phelps AC, Maciejewski PK, Nilsson M, Balboni TA, Wright AA, Paulk $\mathrm{ME}$, et al. Religious coping and use of intensive life-prolonging care near death in patients with advanced cancer. JAMA. 2009;301(11) 1140-1147.doi: 10.1001/jama.2009.341

4. Silvestri GA, Knittig S, Zoller JS, Nietert PJ. Importance of faith on medical decisions regarding cancer care. Journal of clinical oncology. 2003;21(7):1379-1382. doi: 10.1200/JCO.2003.08.036

5. Khosravi M, Nikmanesh Z. Relationship of spiritual intelligence with resilience and perceived stress. Iranian journal of psychiatry and behavioral sciences. 2014;8(4):52-56.

6. Kianpour M. Mental health and hospital chaplaincy: strategies of selfprotection (case study: Toronto, Canada). Iranian journal of psychiatry and behavioral sciences. 2013;7(1):69-77.

7. Burgener SC. Predicting quality of life in caregivers of Alzheimer's patients: the role of support from and involvement with the religious community. Journal of pastoral care. 1999;53(4):433-446.

8. Cohen SR, Mount BM, Tomas JJ, Mount LF. Existential well-being is an important determinant of quality of life. Evidence from the McGill Quality of Life Questionnaire. Cancer. 1996;77(3):576586. doi: 10.1002/(SICI)1097-0142(19960201)77:3<576::AIDCNCR22>3.0.CO;2-0

9. Muir JC, Arnold RM. Palliative care and the hospitalist: an opportunity for cross-fertilization. The American journal of medicine. 2001;111(9B):10S-14S.

10. Fitchett G, Murphy PE, Kim J, Gibbons JL, Cameron JR, Davis JA. Religious struggle: Prevalence, correlates and mental health risks in diabetic, congestive heart failure, and oncology patients. International journal of Psychiatry in Medicine. 2004;34(2):179-196. doi:10.2190/ UCJ9-DP4M-9C0X-835M

11. Best M, Butow P, Olver I. Do patients want doctors to talk about spirituality? A systematic literature review. Patient education and counseling. 2015;98(11):1320-1328. doi: 10.1016/j.pec.2015.04.017

12. Rosmarin DH, Forester BP, Shassian DM, Webb CA, Bjorgvinsson T. Interest in Spiritually Integrated Psychotherapy among Acute Psychiatric Patients. Journal of consulting and clinical psychology. 2015;83(6):1149-1153. doi: 10.1037/ccp0000046

13. Puchalski C, Ferrell B, Virani R, Otis-Green S, Baird P, Bull J, et al Improving the quality of spiritual care as a dimension of palliative care: the report of the Consensus Conference. Journal of palliative medicine. 2009;12(10):885-904. doi: 10.1089/jpm.2009.0142

14. Puchalski CM. Integrating spirituality into patient care: an essential element of person-centered care. Pol Arch Med Wewn. 2013;123(9):491-497.

15. McSherry W, Cash K. The language of spirituality: an emerging taxonomy. International journal of nursing studies. 2004;41(2):151161. doi: 10.1016/S0020-7489(03)00114-7

16. McSherry W, Jamieson S. An online survey of nurses' perceptions of spirituality and spiritual care. Journal of clinical nursing. 2011;20(1112):1757-1767. doi: 10.1111/j.1365-2702.2010.03547
17. Ross L. Spiritual care in nursing: an overview of the research to date. Journal of clinical nursing. 2006 Jul;15(7):852-62. doi: 10.1111/ j.1365-2702.2006.01617

18. Ahmadi F. Culture, religion and spirituality in coping: The example of cancer patients in Sweden. Uppsala: Acta Universitatis Upsaliensis; 2006

19. Taylor EJ. Spirituality, culture, and cancer care. Seminars in oncology nursing. 2001;17(3):197-205.

20. Molzahn AE, Sheilds L. Why is it so hard to talk about spirituality? The Canadian nurse. 2008;104(1):25-29.

21. Bash A. Spirituality: the emperor's new clothes? Journal of clinical nursing. 2004;13(1):11-16. doi: 10.1046/j.1365-2702.2003.00838

22. Viftrup DT, Hvidt NC, Buus N. Spiritually and religiously integrated group psychotherapy: a systematic literature review. Evidence-based complementary and alternative medicine: eCAM. 2013;2013:274625.

23. Lucchetti G, Lucchetti AL. Spirituality, religion, and health: over the last 15 years of field research (1999-2013). International journal of psychiatry in medicine. 2014;48(3):199-215.

24. Ahmadifaraz M, Reisi-Dehkordi N, Mosavizadeh R, Ghaderi S. The Effect of Group Spiritual Intervention Based on the Quran and Prayer on Spiritual Health of Patients with Cancer. J Isfahan Med Sch. 2015;32(320):2454-2463.

25. Asadollahi F, Neshatdoost HT, Kalantary M, Mehrabi HA, Afshar $\mathrm{H}$, Daghaghzadeh H. Effectiveness of spiritual therapy on somatic symptoms in female patients with irritable bowel syndrome. J Res Behav Sci. 2014;12(3):317-327.

26. Bamdad M, Fallahi Khoshknab M, Dalvandi A, Ardakani K, Reza M. Impact of Spiritual Care on Spiritual Health of hospitalized Amphetamin Dependents. Iran J Psychiatric Nurs. 2013;1(3):10-18.

27. Fallahi-Khoshknab M. Effect of Recreational Therapy on Mental Status of Patients with Chronic Schizophrenia. Iran J Psychiatry Clin Psychol. 2007;13(3):232-237.

28. Ghahari S, Fallah R, Bolhari J, Moosavi SM, Razaghi Z, Akbari ME. Effectiveness of cognitive-behavioral and spiritual-religious interventions on reducing anxiety and depression of women with breast cancer. Knowledge Res Appl Psychol. 2012;13(4):33-40.

29. Ghanbzari V, Rahmati M, Beig Mohammadi G, Khaledi Paveh B. Effect's of Group Reading the Quran on Depression of Schizophrenic Patients. Nurs Midwifery J. 2012;6(22):19-25.

30. Gholami A, Beshlideh K. The effect of spiritual therapy on mental health of divorced women. J Fam Couns Psychother. 2012;1(3):331348 .

31. Hamdieh M, Taraghijah S. The Effect of Cognitive Spiritual Group Therapy (CSGT) in Depression. Pajouhandeh J. 2008;13(5):383-389.

32. Kajbaf MB, Rezvani R, Ashoori J. The comparison of effectiveness of spiritual therapy and meta-cognitive therapy on anxiety in girl university students. J Appl Psychol Res. 2013;4(1):1-12.

33. Lotfi Kashani F, Mofid B, Sarafraz MS. Effectiveness of Spirituality Therapy in Decreasing Anxiety, Depression and Distress of Women Suffering from Breast Cancer. Thought Behav Clin Psychol. 2013;7(27):27-36.

34. Lotfi Kashani F, Vaziry S, Arjmand S, Mousavi S, Hashmyh M. Effectiveness of spiritual intervention on reducing distress in mothers of children with cancer. Quarterly J Med ethics. 2012;6(20):174-188. 
35. Saeedi taheri Z, Asadzandi M, Ebadi A. The effect of spiritual care based on GHALBE SALIM model on spiritual experience in patients with coronary artery disease. Iran J Psychiatric Nurs. 2013;1(3):4553.

36. Salajegheh S, Raghibi M. The Effect of Combined Therapy of SpiritualCognitive Group Therapy on Death Anxiety in Patients with Cancer. Shaheed Sadoughi Univ Med Sci. 2014;22(2):1130-1139.

37. Taghadosi M, Fahimifar A. Effect of life review therapy with spiritual approach on the life quality among cancer patients. KAUMS J (FEYZ). 2014;18(2):135-144.

38. Taghizade ME, Miralaie MA. The Study of spiritual group therapy on resiliency in female multiple sclerosis patients in Esfahan. Health Psychol. 2013;2(7):82-102

39. Yaghubi H, Sohrabi F, Mohammadzadeh A. The comparison of cognitive behavior therapy and Islamic based spiritual religion psychotherapy on reducing of student's overt anxiety. J Res Behav Sci 2012;10(2):121-126.

40. Mahdavi B, Fallahi Khoshknab M, Mohammadi F, Hosseini MA. The effect of group spiritual care on quality of life in family caregivers of elders with Alzheimer's disease. Journal of health promotion management. 2015;4(3):34-42.

41. Beiranvand S, Noaparast M, Eslamizade N, Saeedikia S. The effects of religion and spirituality on postoperative pain, Hemodynamic functioning and anxiety after cesarean section. Acta Med Iran. 2014;52(12):909-915.

42. Ebrahimi A, Neshatdoost HT, Mousavi SG, Asadollahi GA, Nasiri H. Controlled randomized clinical trial of spirituality integrated psychotherapy, cognitive-behavioral therapy and medication intervention on depressive symptoms and dysfunctional attitudes in patients with dysthymic disorder. Advanced biomedical research. 2013;2:53. doi: 10.4103/2277-9175.114201

43. Eskandari N, Keshavars M, Ashayeri H, Jahdi F, Hosseini AF. Quran recitation: Short-term effects and related factors in preterm newborns. Res J Med Sci. 2012;6(3):148-153. doi: 10.3923/rjmsci.2012.148.153

44. Hosseini M, Salehi A, Fallahi Khoshknab M, Rokofian A, Davidson PM. The effect of a preoperative spiritual/religious intervention on anxiety in Shia Muslim patients undergoing coronary artery bypass graft surgery: a randomized controlled trial. J Holist Nurs. 2013 Sep;31(3):164-172. doi: 10.1177/0898010113488242

45. Jafari N, Zamani A, Farajzadegan Z, Bahrami F, Emami H, Loghmani A. The effect of spiritual therapy for improving the quality of life of women with breast cancer: A randomized controlled trial. Psychol Health Med. 2013;18(1):56-69. doi: 10.1080/13548506.2012.679738

46. Moeini M, Momeni Ghale Ghasemi T, Yousefi H, Abedi H. The effect of spiritual care on spiritual health of patients with cardiac ischemia. Iranian J Nurs Midwifery Res. 2012;17(3):195-199.

47. Musarezaie A, Moeini M, Taleghani F, Mehrabi T. Does spiritual care program affect levels of depression in patients with Leukemia? A randomized clinical trial. J Educ Health Promot. 2014;3:96. doi: 10.4103/2277-9531.139678

48. Ravaei F, Hosseinian S, Tabatabaei S. Effectiveness of cognitive behavioral and spiritual trainings on improving mental health of
HIV positive drug addicts. Arch Clin Infect Dis. 2013;8(1):23-26. doi: 10.5812/archcid.14378

49. Reihani T, Sekhavat Poor Z, Heidarzadeh M, Mosavi SM, Mazlom SR. The Effect of Spiritual Self-Care Training on Feeling of Comfort in Mothers of Hospitalized Preterm Infants. J Midwifery Reprod Health. 2014;2(2):112-119. doi: 10.22038/JMRH.2014.2261

50. Musarezaie A, Ghasemipoor M, Momeni-Ghaleghasemi T, Khodaee M, Taleghani F. A Study on the Efficacy of Spirituality-Based Intervention on Spiritual Well Being of Patients with Leukemia: A Randomized Clinical Trial. Middle East Journal of Cancer. 2015;6(2):97-105.

51. Zamaniyan S, Bolhari J, Naziri G, Akrami M, Hosseini S. Effectiveness of Spiritual Group Therapy on Quality of Life and Spiritual Well-Being among Patients with Breast Cancer. Iran J Med Sci. 2016;41(2):140144.

52. Shafiee Z, Zandiyeh Z, Moeini M, Gholami A. The Effect of Spiritual Intervention on Postmenopausal Depression in Women Referred to Urban Healthcare Centers in Isfahan: A Double-Blind Clinical Trial. Nursing and midwifery studies. 2016;5(1):e32990. doi: 10.17795/ nmsjournal32990

53. Hedayati E, Hazrati M, Momennasab M, Keshavarzi S. The effect of need-based spiritual/religious intervention on spiritual well-being and anxiety of elderly people. Holist Nurs Pract. 2015;29(3):136-143. doi: 10.1097/HNP.0000000000000083

54. Hosseini L, Lotfi Kashani F, Akbari S, Akbari ME, Sarafraz Mehr S. The Islamic Perspective of Spiritual Intervention Effectiveness on BioPsychological Health Displayed by Gene Expression in Breast Cancer Patients. Iran J Cancer Prev. 2016;9(2):e6360. doi: 10.17795/ijcp6360

55. Richards PS, Bergin AE. A spiritual strategy for counseling and psychotherapy. American Psychological Association. 2005.

56. Tuck I. A critical review of a spirituality intervention. West J Nurs Res. 2012;34(6):712-735. doi: 10.1177/0193945911433891

57. Lines D. Spirituality in counselling and psychotherapy. SAGE. 2006.

58. Hartz GW. Spirituality and mental health: Clinical applications. New York: Haworth pastoral press. 2005.

59. Beck JS. Cognitive behavior therapy: Basics and beyond. Guilford Press. 2011.

60. Pargament KI, Koenig HG, Perez LM. The many methods of religious coping: development and initial validation of the RCOPE. J Clin Psychol. 2000;56(4):519-543.

61. Duigan MM. The Use of the Two Chair Counselling Technique By Ex-Graduates of the Massey University Counselling and Guidance Programme: Completed in Partial Fulfilment of the Master of Counselling Degree. Massey University, Palmerston North. 2010.

62. Enright RD. Forgiveness is a choice: A step-by-step process for resolving anger and restoring hope. American Psychological Association. 2001.

63. Adler MG, Fagley NS. Appreciation: Individual differences in finding value and meaning as a unique predictor of subjective well-being. J Pers. 2005;73(1):79-114. doi: 10.1111/j.1467-6494.2004.00305.x 